PROCESSO DE POSSÍVEL CURA DA INFECÇÃO DA FEBRE AMARELA ATRAVÉS DA LIOFILIZAÇÃO DO MEDICAMENTO LÍQUIDO DO VÍRUS ATENUADO E SUA ADMINISTRAÇÃO NA FLORESTA ATRAVÉS DE PULVERIZAÇÃO

\title{
PROCESS OF POSSIBLE CURE OF YELLOW FE- VER INFECTION THROUGH LYOPHILIZATION OF THE LIQUID DRUG OF THE MITIGATIONAL VIRUS AND ITS ADMINISTRATION IN THE FO- REST THROUGH SPRAYING
}

Wanessa Vilela de Faria Nunes ${ }^{1}$

\begin{abstract}
Resumo: A pesquisa optou pelo objetivo geral de formular o medicamento em grande escala e sua disseminação após a liofilização através da pulverização. E pelos seguintes objetivos específicos: aplicar a metodologia em laboratório específico; avaliar o nível de cura através da pulverização no mosquito em larga escala; determinar a possível cura através

da pesquisa. O mosquito aedes aegypti é o transmissor principal do vírus da febre amarela nas cidades, este vírus está presente também em florestas, o vírus por sua vez contamina o mosquito que por sua vez pica o macaco, que então começa a sofrer com a doença. Aí surge o problema: um inseto livre do vírus que chupa o sangue desse primata contami-
\end{abstract}

1 Licenciatura Plena em Química

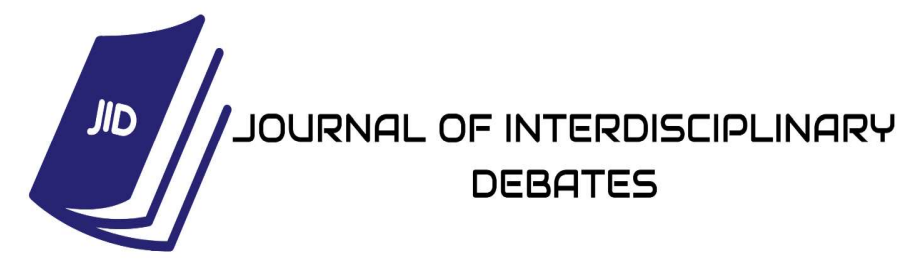


ISSN: 2675-469X

Vol. 02 - n 04 - ano 2021

Editora Acadêmica Periodicojs

nado passa a carregar o causador da febre amarela. E então pode transmiti-lo para outro macaco, que pode espalhá-lo a outro mosquito, nas regiões de mata, os insetos dos gêneros Haemagogus ou Sabethes picam macacos com a doença e, então, podem passá-la a seres humanos nas redondezas. É plausível que o Aedes Aegypti dissemine a febre amarela nas cidades, é um círculo vicioso que já ocorre há muitos e muitos anos nas matas brasileiras. Os mosquitos dos gêneros Haemagogus e Sabethes só circulam por áreas de mata. Agora, se uma pessoa visita uma floresta ou mora perto de outra, por exemplo, pode ser picada por um desses mosquitos infectados. E, aí, corre o risco de ter febre amarela silvestre.

Palavras-chave: aedes aegypti, contamina, vírus
Abstract: The research chose the general objective of formulating the drug on a large scale and its dissemination after lyophilization through spraying. And for the following specific objectives: apply the methodology in a specific laboratory; assess the level of cure through large-scale mosquito spraying; determine the possible cure through research. The aedes aegypti mosquito is the main transmitter of the yellow fever virus in cities, this virus is also present in forests, the virus in turn infects the mosquito which in turn bites the monkey, which then begins to suffer from the disease. Then the problem arises: a virus-free insect that sucks the blood of this contaminated primate starts carrying the cause of yellow fever. And then it can transmit it to another monkey, which can spread it to another mosquito, in the wooded regions,

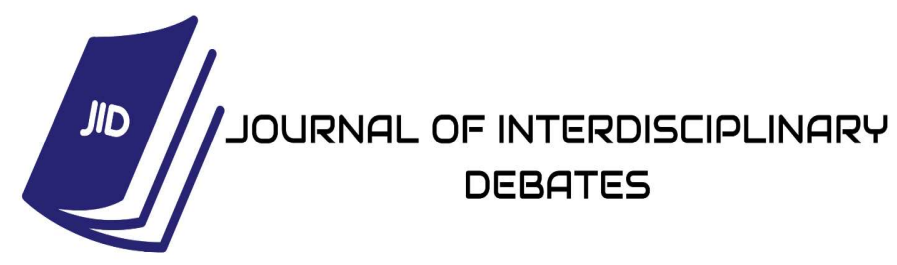


ISSN: 2675-469X

Vol. 02 - n 04 - ano 2021

Editora Acadêmica Periodicojs

insects of the genera Haemagogus or Sabethes bite monkeys with the disease and then they can pass it on to humans in the surroundings. It is plausible that Aedes Aegypti spreads yellow fever in cities, it is a vicious circle that has been taking place for many, many years in the Brazilian forests. Mosquitoes of the genera Haemagogus and Sabethes only circulate in forest areas. Now, if a person visits one forest or lives close to another, for example, they can be bitten by one of these infected mosquitoes. And then you run the risk of getting wild yellow fever.

Keywords: aedes aegypti, contaminate, virus

\section{INTRODUÇÃO}

O mosquito aedes aegypti é o transmissor principal do vírus da febre amarela nas

cidades, este vírus está presente também em florestas, o vírus por sua vez contamina o mosquito que por sua vez pica o macaco, que então começa a sofrer com a doença. Aí surge o problema: um inseto livre do vírus que chupa o sangue desse primata contaminado passa a carregar o causador da febre amarela. E então pode transmiti-lo para outro macaco, que pode espalhá-lo a outro mosquito, nas regiões de mata, os insetos dos gêneros Haemagogus ou Sabethes picam macacos com a doença e, então, podem passá-la a seres humanos nas redondezas. É um círculo vicioso que já ocorre há muitos e muitos anos nas matas brasileiras. $\mathrm{O}$ número de mortes ocasionadas pelo vírus é significativo, causando dor à muitas famílias, podendo causar uma epidemia ou pandemia em números incalculáveis de seres

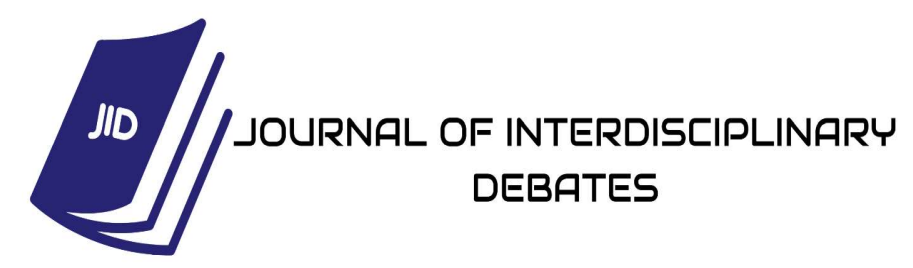


ISSN: 2675-469X

Vol. 02 - n 04 - ano 2021

Editora Acadêmica Periodicojs

humanos.

procedimento de pulverizar o re-

Por essa razão, o presultado do mesmo.

sente projeto foca sua pesquisa

A pesquisa optou pelo nos seguintes questionamentos: objetivo geral de formular o meComo efetuar a pesquisa no ladicamento em grande escala e boratório específico? Como verificar a presença do vírus? Como determinar a cura?

Essa pesquisa foi desenvolvida através de produtos liofilizados que são: antibióticos, bactérias, soros, vacinas, medicamentos para diagnóstico, produtos contendo proteínas e biotecnológicos, células e tecidos e produtos químicos. $\mathrm{O}$ produto a ser desidratado é congelado sob pressão atmosférica. Depois, em uma fase de secagem inicial - definida como secagem primária a água (em gelo) é removida por sublimação; na segunda fase - secagem secundária - ela é removida por dessorção. A liofilização é realizada sob vácuo. Após isso ocorreria a pulverização que é o sua disseminação após a liofilização através da pulverização. E pelos seguintes objetivos específicos: aplicar a metodologia em laboratório específico; avaliar o nível de cura através da pulverização no mosquito em larga escala; determinar a possível cura através da pesquisa.

Fator determinante na escolha do tema, foi o surgimento da ideia única e peculiar da autora, procurando uma solução para a doença viral devastadora que é a febre amarela.

Portanto, o presente estudo tem por justificativa a ideia da pesquisa, porque o número de mortes ocasionadas pelo vírus é significativo, causando dor à muitas pessoas. A aplicação do

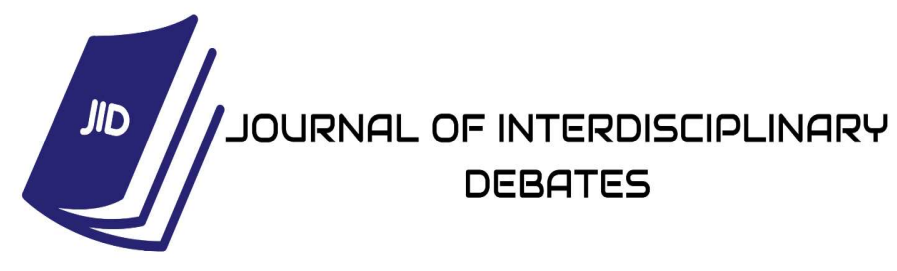


ISSN: 2675-469X

Vol. 02 - n 04 - ano 2021

Editora Acadêmica Periodicojs

processo de liofilização focou-se, posteriormente, no campo da indústria farmacêutica, ocorrendo durante a década de 1950 o surgimento de medicamentos liofilizados como antibióticos à base de penicilina 19 (KUMAR et al., 2011). Paralelo ao surgimento das penicilinas liofilizadas, pesquisas acerca da liofilização de peptídeos, proteínas, anticorpos, enzimas e hormônios foram sendo aprofundadas, e posteriormente comercializadas com fins terapêuticos. A partir disso, surgiram as vacinas liofilizadas, os antibióticos e também as vitaminas (TERRONI et al., 2011)

Todo esse processo é desenvolvido e metodicamente calculado para que haja uma possível cura vacinando o mosquito através da pulverização com o medicamento do vírus atenuado da febre amarela liofilizado, ou seja, em forma de pó.
Este trabalho foi realizado através de um estudo qualitativo, quantitativo, descritivo, documental e de caráter retrospectivo de revisão bibliográfica. Serão utilizados artigos científicos constantes de 2010 a 2018 em vários sites de bases de dados, tais como: Scielo, Bireme, entre outros portais pertinentes. Além destas fontes on-line, serão utilizados sites de organizações nacionais e internacionais de referência especializados sobre o assunto.

A pesquisa qualitativa, de acordo com Wilhelm Wundt (1920) trata-se de um método de pesquisa que foca o modo como indivíduos e grupos de indivíduos veem e entendem o mundo ou uma parte específica dele, e como constroem significado e conhecimento, quantitativa, numa pesquisa em que a abordagem é basicamente quantitativa,

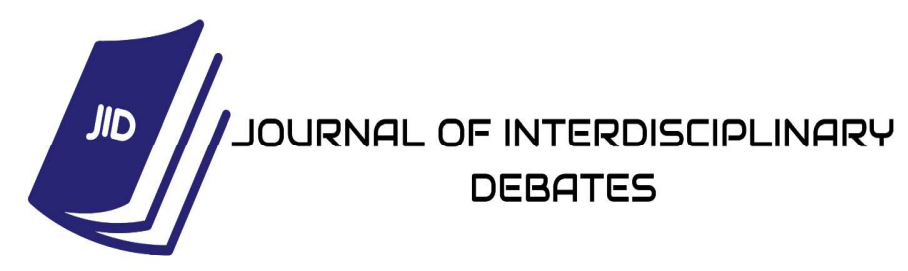


o pesquisador se limita à descrição fatual deste ou daquele evento, ignorando a complexidade da realidade social (FRANCO, 1985:35).

Descritivo, o tipo de pesquisa que se classifica como "descritiva", tem por premissa buscar a resolução de problemas melhorando as práticas por meio da observação, análise e descrições objetivas, através de entrevistas com peritos para a padronização de técnicas e validação de conteúdo (THOMAS; NELSON; SILVERMAN, 2009).

Com a liofilização do medicamento líquido do vírus atenuado da febre amarela, podemos aplica-lo de forma pulverizante, ou seja, pulverizar as florestas na época de frio, pois é nessa época em que o mosquito se propaga com maior velocidade, em virtude de tentativa de eliminar o vírus presente no mosquito aedes aegypti, mas especificamente nas espécies dos gêneros Haemagogus ou Sabethes, lembrando que esta pulverização não é uma eliminação em massa dos mosquitos, pois os mesmos não serão destruídos, a ideia basicamente é vacinar o mosquito através do ar, com sua respiração o mosquito absorveria o medicamento liofilizado e seria automaticamente vacinado.

\section{DESENVOLVIMENTO}

\section{Princípios Básicos da Liofiliza-} ção Farmacêutica

A secagem por congelamento também conhecida como liofilização é usada principalmente para remover água de produtos sensíveis, a maioria biológicos, sem danificá-los. Como tal, eles podem ser preservados em um estado de armazenamen-

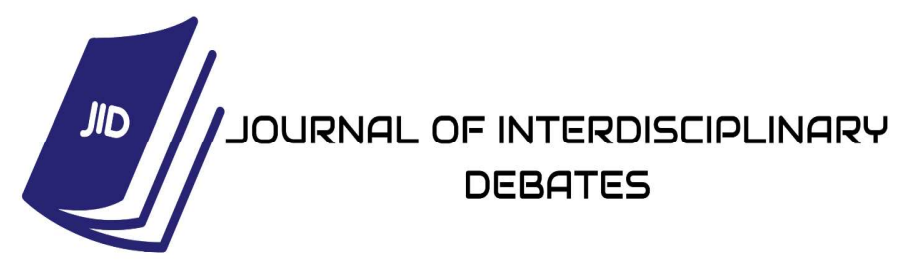


ISSN: 2675-469X

Vol. 02 - n 04 - ano 2021

Editora Acadêmica Periodicojs

to permanente e serem posteriormente reconstituídos substituindo a água. As condições em que o processo ocorre determinarão a qualidade do produto liofilizado.

\section{Alguns aspectos importantes que devem ser considerados du- rante o processo de liofilização.}

\section{Congelamento}

O produto básico será transformado por abstração do calor para criar um estado que seja adequado para a secagem por sublimação. Quando um produto aquoso é resfriado, são formados núcleos de cristal. A água circundante é fixada ao redor dos locais de nucleação, resultando em cristais de diferentes tamanhos e formas. A velocidade de congelamento, a composição do produto de base, o teor de água, a viscosidade do líquido e a presença de substâncias não-cristalizadas são todos fatores decisivos na determinação da forma e tamanho do cristal, e influenciam o processo de sublimação seguinte. Grandes cristais compreendem uma pós-sublimação com estrutura relativamente aberta, deve-se considerar que os pequenos cristais de gelo contêm pequenos espaços no produto seco, o que diminui a remoção do vapor de água.

$\mathrm{O}$ ponto de congelamento da água pura é de $0^{\circ} \mathrm{C}$. Quaisquer outras substâncias dissolvidas na água abaixarão o ponto de congelamento. Quando há presença de sais inorgânicos, ele pode ser consideravelmente menor. Se uma solução fraca é congelada, o gelo puro irá se separar inicialmente, aumentando assim a concentração da substância dissolvida na solução residual (além de reduzir o ponto de congelamento). $\mathrm{O}$ efeito desta

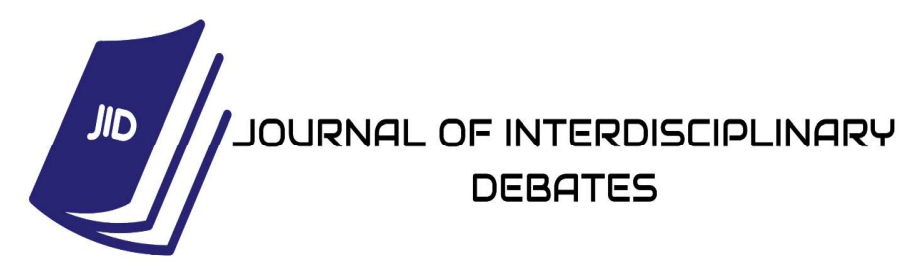


ISSN: 2675-469X

Vol. 02 - n 04 - ano 2021

Editora Acadêmica Periodicojs

concentração do produto varia de caso a caso e deve ser levado em conta na seleção da técnica de congelamento mais adequada.

A técnica de congelamento mais adequada para um determinado produto deve ser determinada e seus parâmetros reconhecidos antes da secagem por sublimação. O comportamento do congelamento do produto pode ser investigado, por exemplo, usando o método de medição da resistência. Dois métodos de congelamento diferentes são usados para produtos farmacêuticos: congelamento por contato com superfície resfriada; ou congelamento por rotação/dinâmico em um banho refrigerante.

O primeiro método é uma técnica de congelamento estático no qual um liofilizador deve ser capaz de ajustar a taxa de congelamento ao produto específico e controlar a velocidade do congelamento. Uma temperatura final de $-50^{\circ} \mathrm{C}$, em alguns casos, será suficiente para satisfazer a maioria das necessidades. $\mathrm{O}$ segundo método é usado sempre que grandes quantidades de um produto líquido devem ser congelados e secos em frascos ou garrafas grandes. A técnica de congelamento adequada também irá oferecer um produto congelado que é adequado para sublimação, isto é, um produto uniforme e tão fino quanto possível para que o tempo de secagem seja curto.

\section{Secagem Primária}

No início da fase de secagem primária, a sublimação do gelo ocorre na superfície do produto. Com a continuação do processo, a superfície de sublimação volta-se para o produto e o vapor resultante deve ser conduzido através de camadas ex-

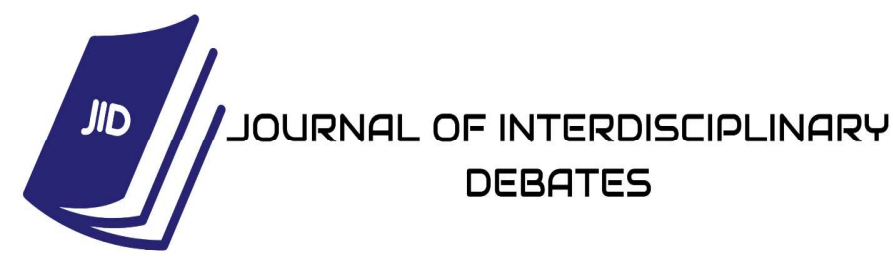


ISSN: $2675-469 \mathrm{X}$

Vol. 02 - n 04 - ano 2021

Editora Acadêmica Periodicojs

teriores previamente secas. Isso significa que o processo de secagem depende da velocidade de transferência e remoção dos vapores, bem como o calor necessário para sublimação. $\mathrm{O}$ calor necessário para a sublimação é fornecido por convecção e condução térmica e, em menor grau, por radiação térmica.

Além da transferência de calor por condução térmica e radiação, a transferência de calor por convecção deve ser otimizada. É de notar, no entanto, que convecção quase cessa em pressões abaixo de 10-2 mbar. por este motivo, como uma função da temperatura necessária para a sublimação, a pressão na câmara de secagem é ajustada durante a secagem primária para o maior valor admissível. O calor da sublimação não é necessário na superfície do produto, mas no limite do núcleo do gelo, que se retira para o centro do produto conforme a secagem avança.

Embora o vapor de água flua do interior do produto para o exterior, a transferência de calor deve ir na direção oposta. Devido a baixa condutividade térmica das camadas de produto seco, o gradiente de temperatura necessário para transferência de calor aumenta de forma constante. Para evitar danos ao produto, a temperatura máxima possível para o produto seco não deve ser excedida. Por outro lado, deve-se tomar cuidado para manter a temperatura de sublimação necessária durante a secagem; manter o fornecimento de calor no limite do núcleo do gelo em equilíbrio e evitar o superaquecimento da zona de sublimação. A fase de secagem primária continua até que todo o gelo no produto tenha sido sublimado.

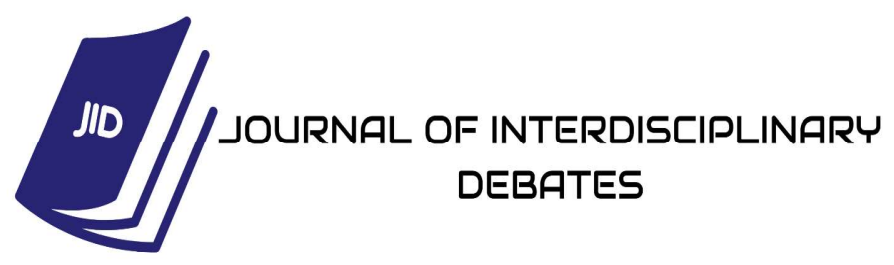


ISSN: 2675-469X

Vol. 02 - n 04 - ano 2021

Editora Acadêmica Periodicojs

\section{Secagem Secundária}

$\mathrm{Na}$ fase de secagem secundária ou final, o teor de umidade residual é reduzida tanto quanto possível, a fim de assegurar que o produto esteja em um estado de armazenamento permanente. A água que adere por adsorção na superfície interna do produto tem que ser removida. Para isso, muitas vezes é necessário ultrapassar as forças capilares da água. A fábrica de liofilização deve, por conseguinte, ser projetada para produzir um elevado gradiente de pressão durante a fase de secagem secundária (na maioria dos casos, não é possível aumentar a temperatura sem causar danos ao produto). $\mathrm{O}$ processo de secagem secundário deve ser precisamente controlado para evitar o excesso de secagem do produto.

\section{Após Tratamento}

Esta seção se refere à maneira pela qual o produto seco (frequentemente muito higroscópico) pode ser protegido após a secagem. Se o produto é seco em garrafas, frascos ou ampolas, é útil fechar esses recipientes imediatamente após a secagem antes da remoção da fábrica. Para este efeito, rolhas de borracha com tiras especiais são colocadas no gargalo das garrafas ou frascos antes de carregar a fábrica e, quando secas, são firmemente pressionadas nos gargalos por um dispositivo de rolhamento. Os recipientes podem ser selados sob vácuo ou atmosfera de gás de proteção. A escolha do método depende do produto. É aconselhável, em qualquer caso, ventilar a câmara de secagem com nitrogênio seco ou gás inerte (até

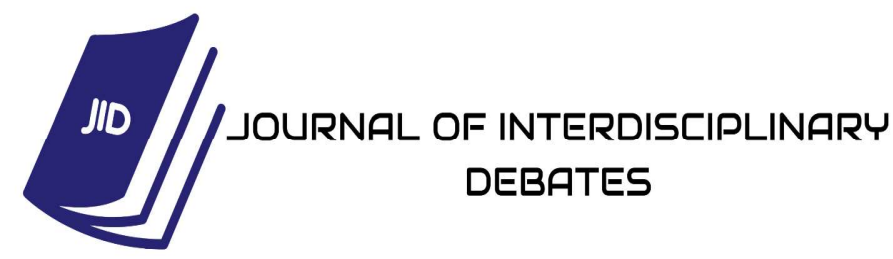


ISSN: $2675-469 \mathrm{X}$

Vol. 02 - n 04 - ano 2021

Editora Acadêmica Periodicojs

à pressão atmosférica) no final

do processo e não usar ar muito

úmido para ventilação.

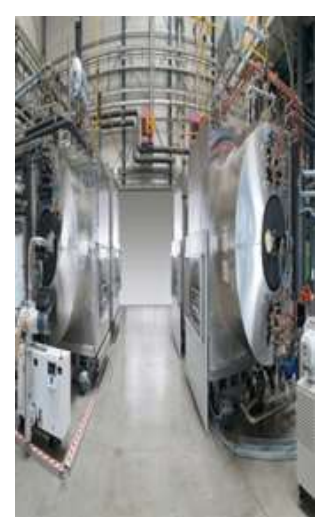

Os recipientes podem substância líquida em partículas ser selados sob vácuo ou atmosdiminutas ou a converter algo em fera de gás de proteção. A escopó. Em sentido figurado, pulverilha do método depende do produzar significa destruir algo. $\mathrm{O}$ conto. É aconselhável, em qualquer ceito de pulverização seja usado caso, ventilar a câmara de secacom referência a um aerossol.

A ideia de pulverização inerte (até à pressão atmosférica) agrícola é usada relativamente no final do processo e não usar à atividade desenvolvida pelos ar muito úmido para ventilação. aviões e pelas máquinas que fuPulverização é o procedimento migam os campos. A fumigação, de pulverizar o resultado do mesdeste modo, implica propagar almo. Significa disseminar uma gum tipo de praguicida através

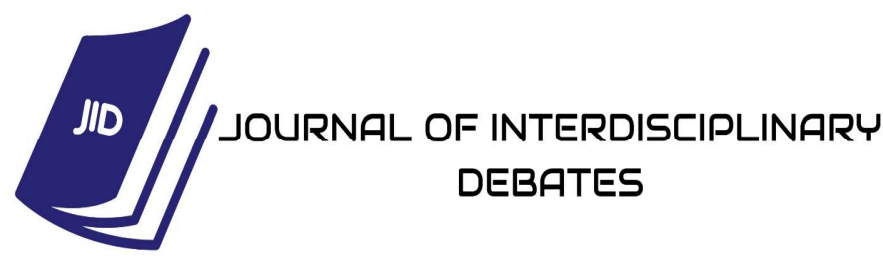


Vol. 02 - n 04 - ano 2021

Editora Acadêmica Periodicojs

da sua pulverização sobre o ter- lugar pelas colisões entre os áto-

reno.

mos e os aviões.

Pulverização catódica, por sua vez, é aquela que tem lugar quando se aplicam aviões energéticos sobre um sólido, proConhecendo as Epizootias da FA - Febre amarela no país e recomendações de vacinações vocando a vaporização dos átomos que fazem parte do material em questão. Este processo tem

Epizootias confirmadas para FA Epizootias em investigação para FA
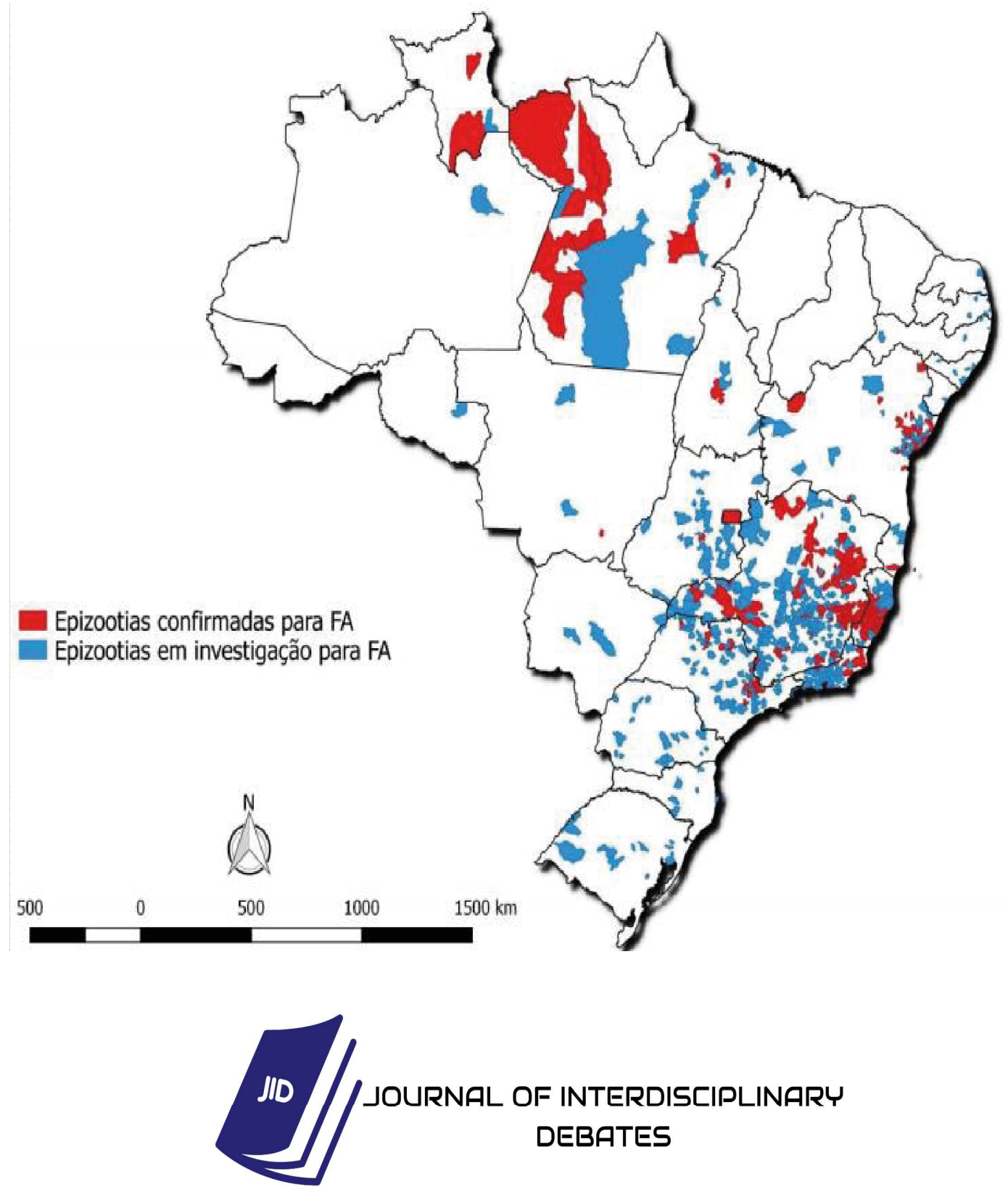


\section{A FEBRE AMARELA NO PAÍS}
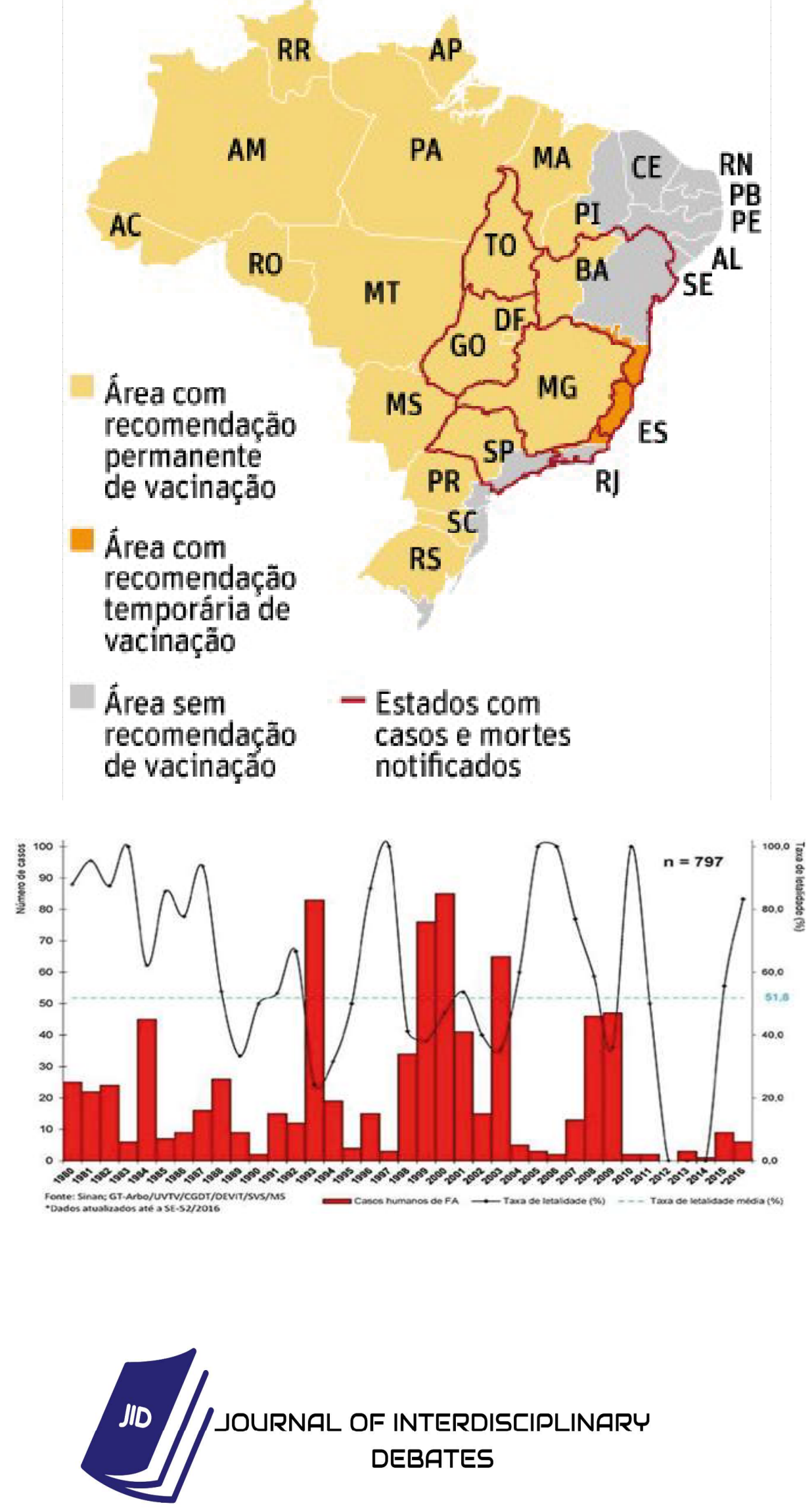
CONSIDERAÇÕES FINAIS

A pesquisa foi desenvolvida através da ideia de que vacinar os macacos e os seres humanos contra o vírus da febre amarela não seria a solução, já que o único reservatório existente é o mosquito, passando assim a febre amarela a seus hospedeiros macacos e seres humanos. A solução básica que traz o projeto é a "vacinação" do reservatório primário, ou seja, os mosquitos Haemagogus, Sabethes ou aedes aegypti. Segundo Costa \& Ferreira (1991) apud (SOLA, 2012), os métodos de manutenção de microorganismos podem ser classificados de acordo com o tempo máximo de preservação: métodos de curto prazo (repique contínuo), métodos de médio prazo (preservação em óleo mineral, preservação em água esterilizada, congelamento a $20^{\circ} \mathrm{C}$, e seca- gem em sílica, solo, papel filtro), e os métodos de longo prazo (liofilização, congelamento a $80^{\circ} \mathrm{C}$ e criopreservação em nitrogênio líquido).

A liofilização tem sido proposta como um método alternativo para preservação de sêmen, visto que já é uma técnica amplamente utilizada para conservação de vários materiais: alimentos, medicamentos, vacinas, materiais biológicos, plasma sanguíneo (HOCHI et al., 2011).

As vantagens da liofilização incluem: menor custo de armazenamento, possibilidade de conservação de linhagens, espécies, raças raras ou mesmo linhagens transgênicas, e aprofundamento nos estudos de caracterização de espécies - raças por meio de marcadores genéticos, porém que também são encontradas nos métodos de preservação convencionais

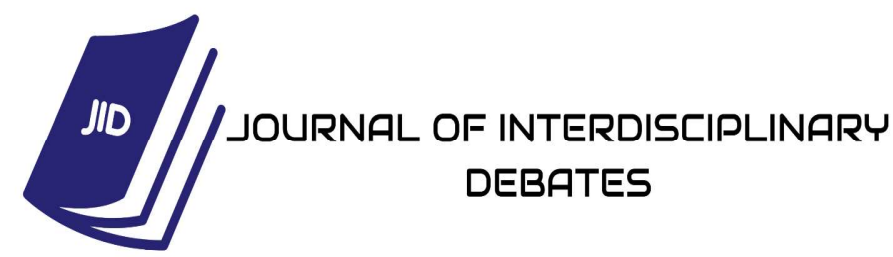


ISSN: $2675-469 \mathrm{X}$

Vol. 02 - n 04 - ano 2021

Editora Acadêmica Periodicojs

(MARTINS, 2006).

A liofilização, criodesidratação, ou congelamento a seco, é uma forma alternativa de preservação celular. Pode ser definida como o processo de secagem de uma substância congelada, no qual a maior parte da água é removida por sublimação (MARTINS, 2006).

Historicamente, o primeiro produto liofilizado surgiu em 1911, com o vírus da raiva (TERRONI et al., 2011). Porém só atingiu a escala industrial durante a Segunda Guerra Mundial (1939-1945), devido à demanda por plasma sanguíneo. Entretanto, nesta época já havia a comercialização de café em pó, que surgiu em 1938, pela companhia Nestlé (WARD, 2012).

\section{REFERÊNCIAS}

BRASIL. Ministério da Saúde.
Secretaria de Vigilância em Saúde. Guia de Vigilância em Saúde. 8. ed. Brasília: MS/SVS, 2014. Cap 6: Febre Amarela, p. 419- 36.

BRASIL. Departamento de Vigilância das Doenças Transmissíveis. Coordenação- Geral do Programa Nacional de Imunizações. Coordenação Geral de Doenças Transmissíveis. Nota Informativa $n^{\circ} 143 / 2014 . M S / S V S / D V D T /$ CGPNI Recomendações da vacinação contra febre amarela, após declaração da Organização Mundial da Saúde. Brasília: MS/SVS/ DVDT/CGPNI, 2014.

BRASIL. Secretaria de Vigilância em Saúde. Departamento de Vigilância das Doenças Transmissíveis. Manual de vigilância epidemiológica de eventos adversos pós-vacinação. Brasília: MS/ SVS/DVDT/CGPNI, 2014.

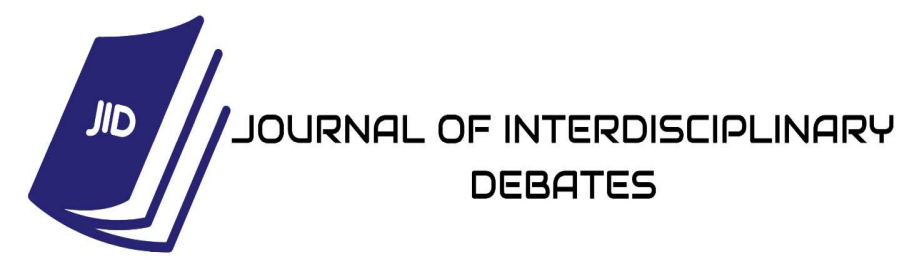


BRASIL. Ministério da Saúde. Parecer n. 05, de 2015. Disponível em: http://www.anvisa.gov. br/HOTSITE/VIAJANTE/ VACINAFEBREAMARELA.PDF. Acessado em: 16 fev. 2018.

\section{BRASIL. Febre amarela.}

Situação epidemiológica.

Disponível em: http://portalsaude.saude.gov.br/index.php/ situacaoepidemiologica-dados febreamarela. Acessado 06 fev. 2018.

CENTERS for Disease Control and Prevention. MMWR. Yellow Fever Vaccine - Recommendations of the Advisory Committee on Immunization Practices (ACIP). 2010;59 (RR-7). Disponível em: https://www.cdc.gov/ mmwr/pdf/rr/rr5907.pdf. Acessado em 06 fev. 2017.

CENTERS for Disease Contro and Prevention. MMWR. Yellow Fever Vaccine Booster doses: Recommendations of the Advisory Committee on Immunization Practices, 2015;64(23):647- 50. Disponível em: https://www.cdc. gov/ mmwr/pdf/wk/mm6423. pdf. Acessado em 06 fev. 2017.

INTERNATIONAL Society for Infectiuos Diseases. ProMED mail. Disponível em: http://www. promedmail.org/pt. Acessado em 16 jan. 2018.

MONATH, T.P. \& VASCONCELOS, P.F. Yellow fever. J Clin Virol, 2015;64:160-173.

SOCIEDADE BR A SILEIR A DE IMUNIZAÇÕES (SBIm). Calendários de Imunização. Disponível em: http://sbim.org.br/calendarios-de-vacinacao. Acessado em 21 jan. 2018.

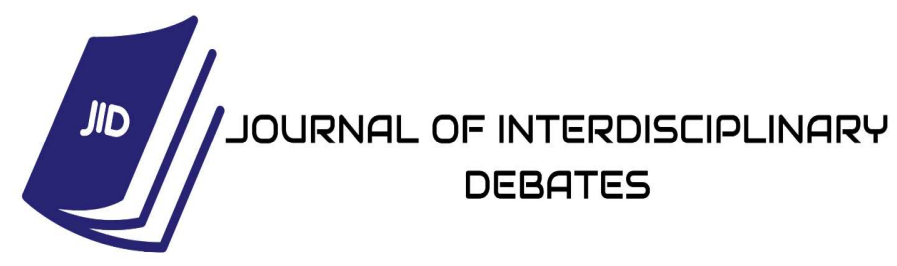


ISSN: 2675-469X

Vol. 02 - n 04 - ano 2021

Editora Acadêmica Periodicojs

SOCIEDADE BR ASILEIR A

DE IMUNIZAÇÕES

(SBIm). Nota Técnica - Febre

Amarela. Disponível em http://

sbim.org.br/images/fi les/ ntfe-

breamarelasbim.pdf. Acessado em 06 fev. 2018.

SOCIEDADE BRASILEIRA

DE INFECTOLOGIA (SBI). In-

formativo para Profi ssionais da

Saúde. Disponível em: http://ab-

manacional.com.br/wp- content/

uploads/2017/02/Informativo

Febre_Amarela_Profi ssionais de_saude-1.pdf. Acessado em 06 fev. 2018.

SOCIEDADE BRASILEIRA DE PEDIATRIA (SBP). Calendário de vacinação SBP 2016. Disponível em: http://www.sbp.com. br/src/ uploads/2016/08/Calendario- Vacinacao2016-19out16.pdf. Acessado em 06 fev. 2018.
TAUIL P. L. Controle da febre amarela no Brasil. Revista Saúde Pública. 2010;44(3):555-8.

WORLD HEALTH ORGANIZATION. Yellow fever. Fact sheet. May 2016. Disponível em: http://www. who.int/mediacentre/factsheets/fs100/en. Acessado em 15 jan. 2018.

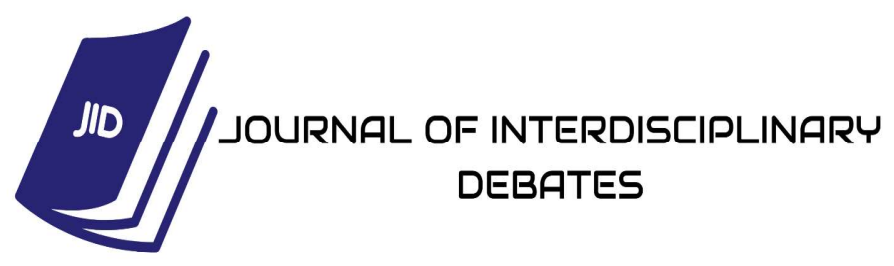

